\author{
Denise J. Hills
}

\title{
Be a Voice for Science
}

Geological Society of America

Annual Meeting 2019 


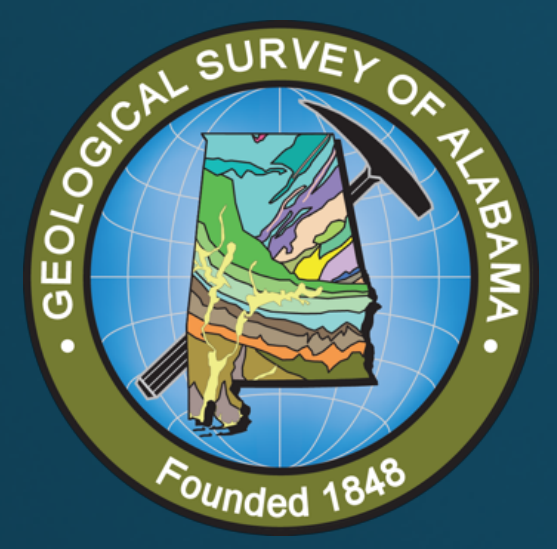

Explore, characterize and report on natural resources to support prudent economic development, conservation, management, and public policy for the betterment of Alabama's citizens, communities, and businesses

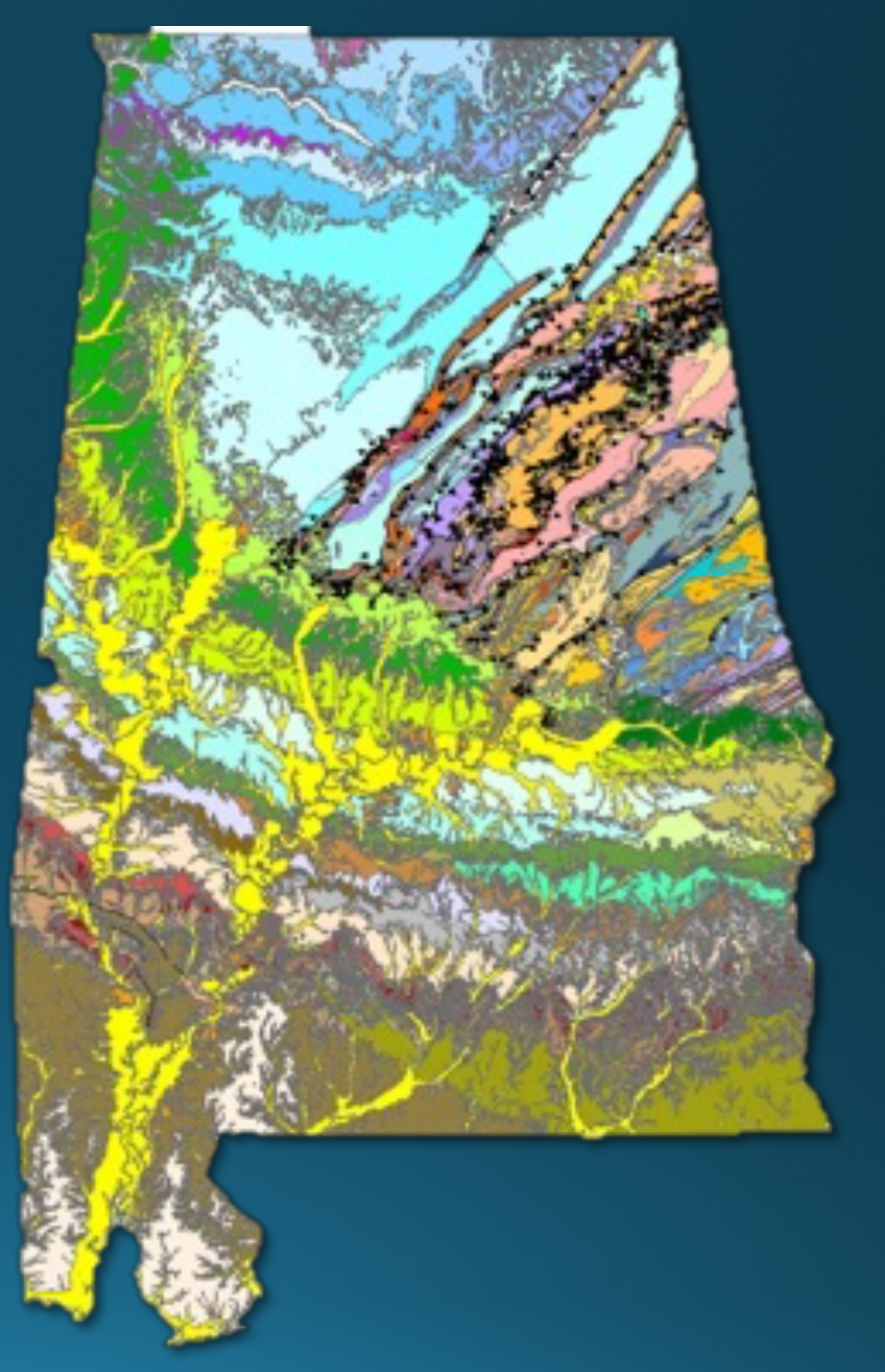


What I thought it would be like

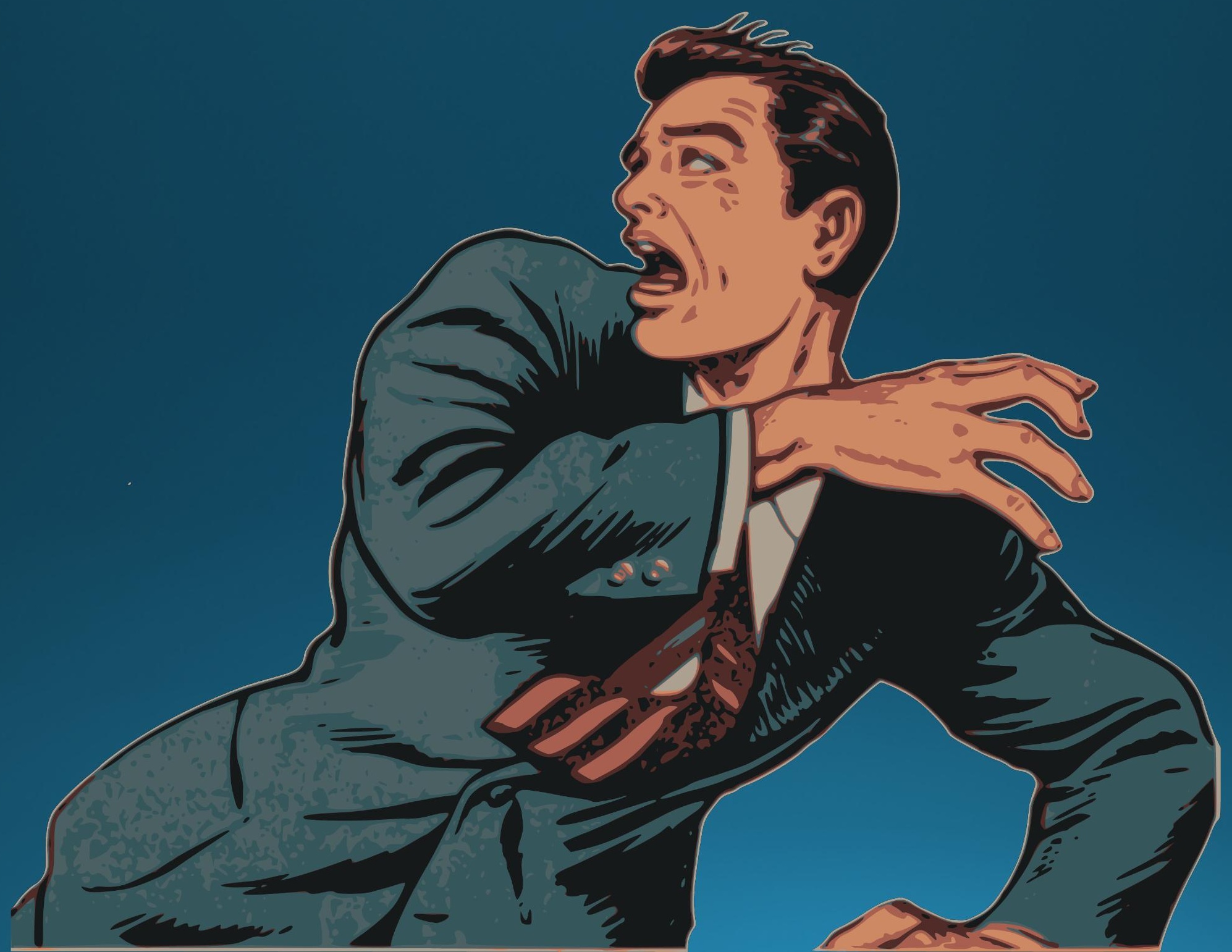




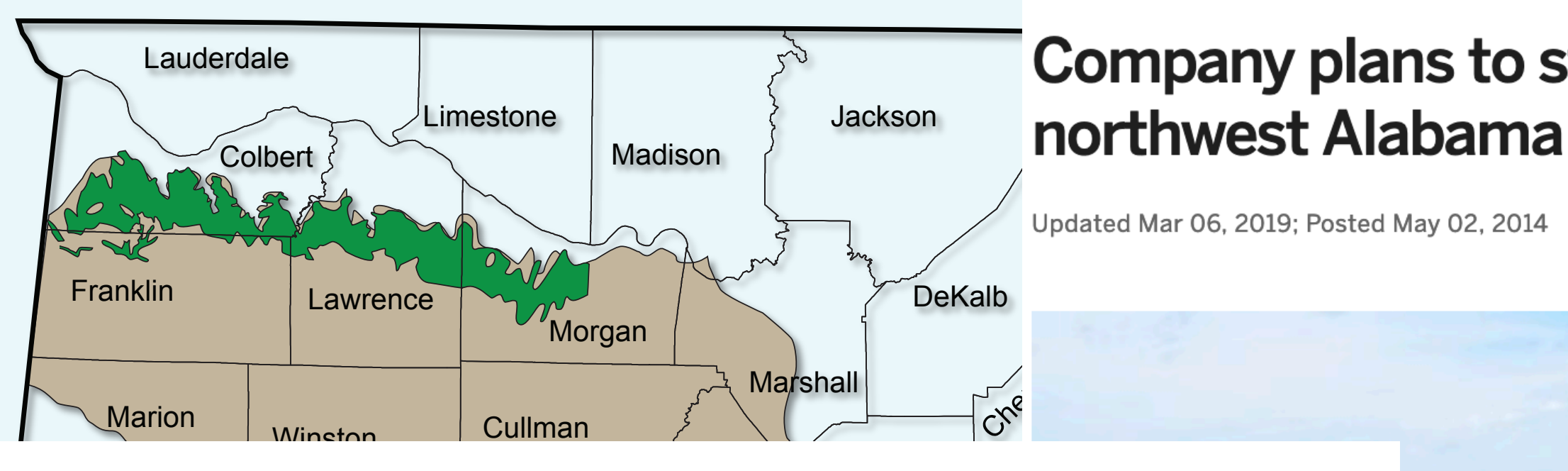

Company plans to strip mine oil sands in northwest Alabama

Updated Mar 06, 2019; Posted May 02, 2014

(ㄷ) 5 years ago

Give us a break with that garbage - there is absolutely NOTHING good about this. Nothing!
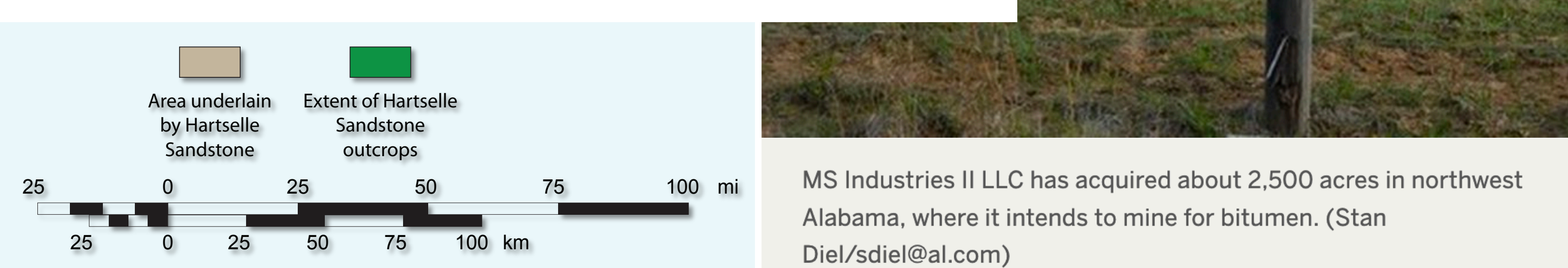

MS Industries II LLC has acquired about 2,500 acres in northwest Alabama, where it intends to mine for bitumen. (Stan Diel/sdiel@al.com) 


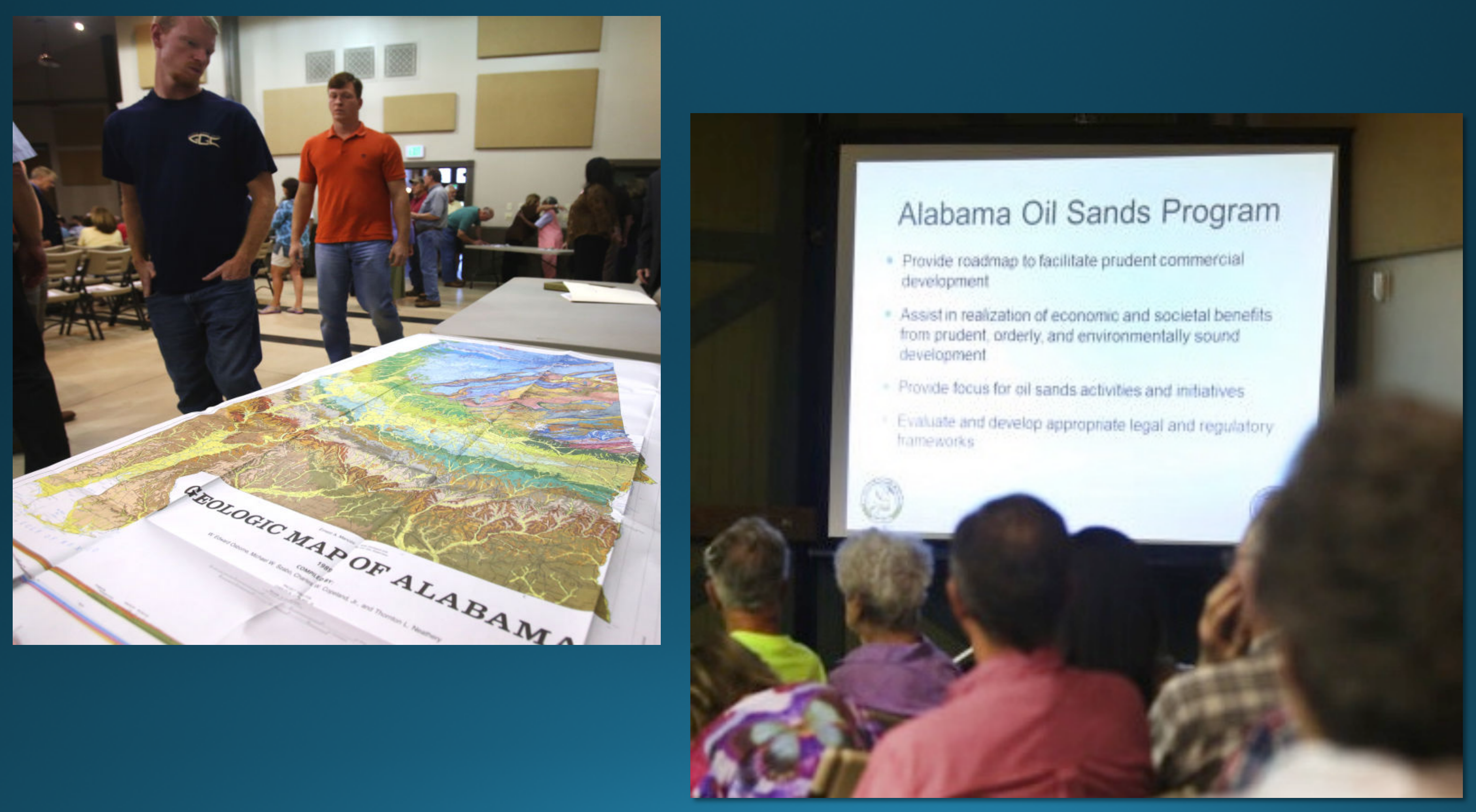




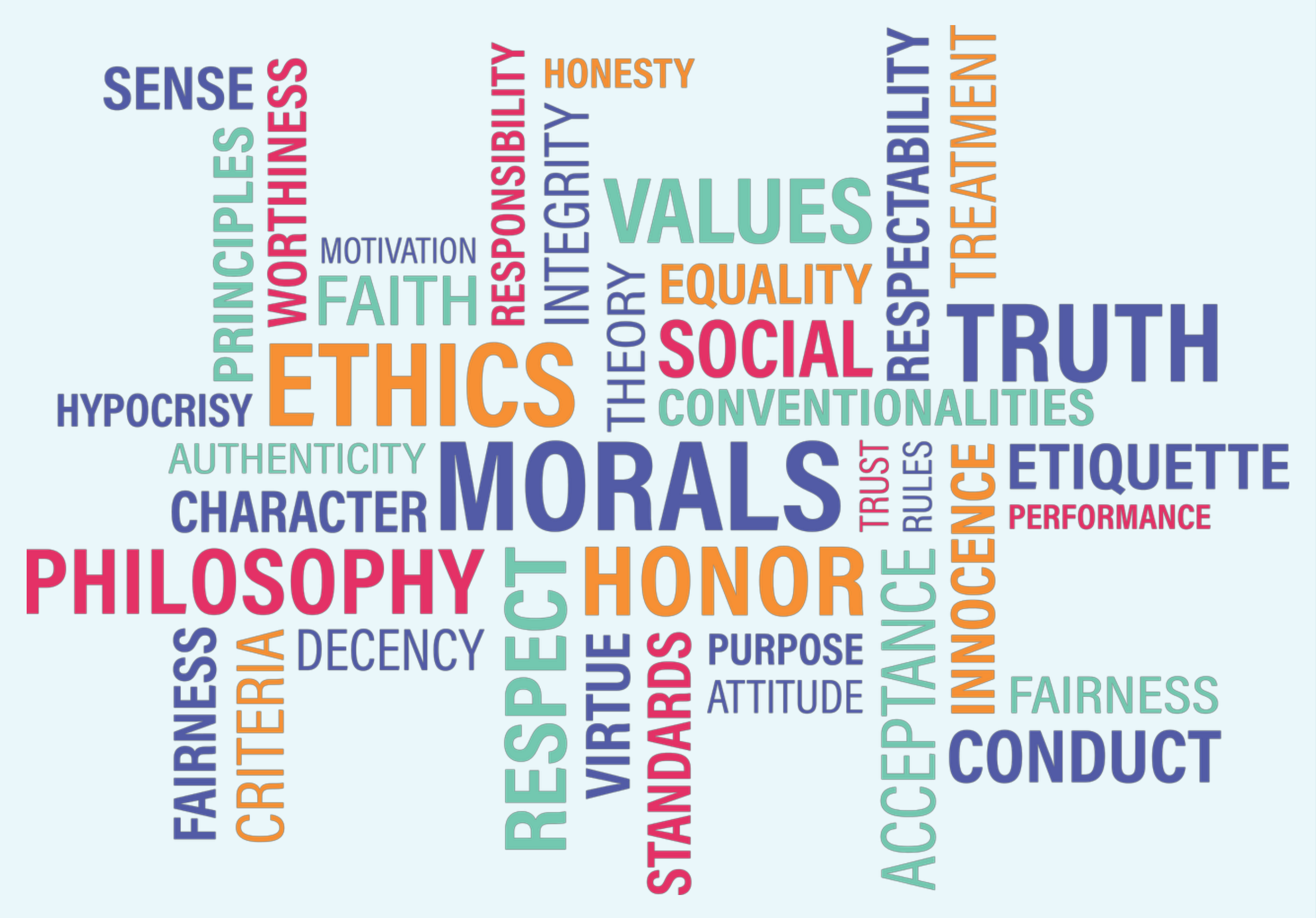




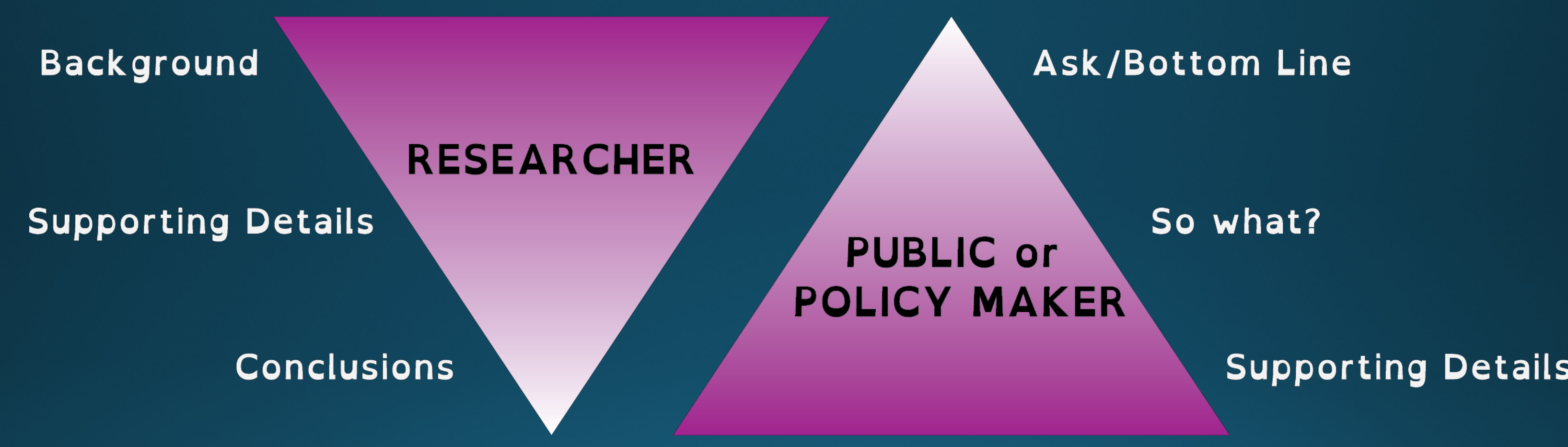




\section{Geoscience Energy Research in Alabama}

Basic and applied energy resources research is vital to the US attaining energy independence.

The Geological Survey of Alabama (GSA) is a state government agency established in 1848, and provides service and information to Alabama and its citizens as a natural resource data gathering and research agency. As part of its mission, GSA is mandated to explore for, characterize, and report Alabama's mineral, energy, water, and biological resources in support of economic development, conservation, management, and public policy for the betterment of Alabama's citizens, communities, and businesses. Researchers at GSA conduct basic and applied research in these fields.

The GSA has a sister agency, the State of Alabama Oil and Gas Board (OGB), a regulatory agency with the statuto preventing waste and promoting the conservation of oil and gas while ensuring the protection of both the env the correlative rights of owners. The Board is granted broad authority in Alabama oil and gas conservation promulgate and enforce rules and regulations to ensure the conservation and proper development of Alabama resources.

\section{Energy Resource Assessment}

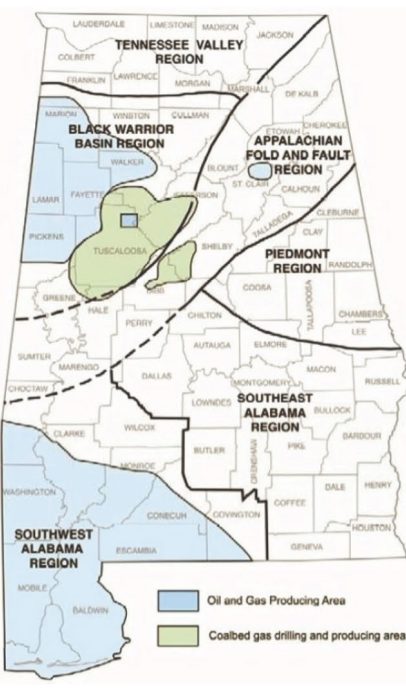

Alabama has a rich history of hydrocarbon energy resources. Not only are reserves the state has been at the forefront of Unconventional energy rese through the Research Partnership to Secure Energy for America (RPSEA) pr potential production of natural qas from and characteristics of shale formation The natural energy resources in Alabama do not stop at the coastline, production taking place in the state and federal waters of the Gulf of Mexico. T by the GSA on these offshore resources, often funded by federal agencies Energy Management, provides needed information to companies interested providing a check to ensure royalties and fees are appropriately assessed and $p$ Hydrocarbons are not the only potential energy source in the state, however. cooperation with the Association of American State Geologists, supported re Geothermal Data System (NGDS), a nationwide data catalog that provides in resources located within the U.S. Agencies, businesses, and researchers use th known geotherma resources, which can lead to atternative energy developm work contributes to the US's goal of energy independence.

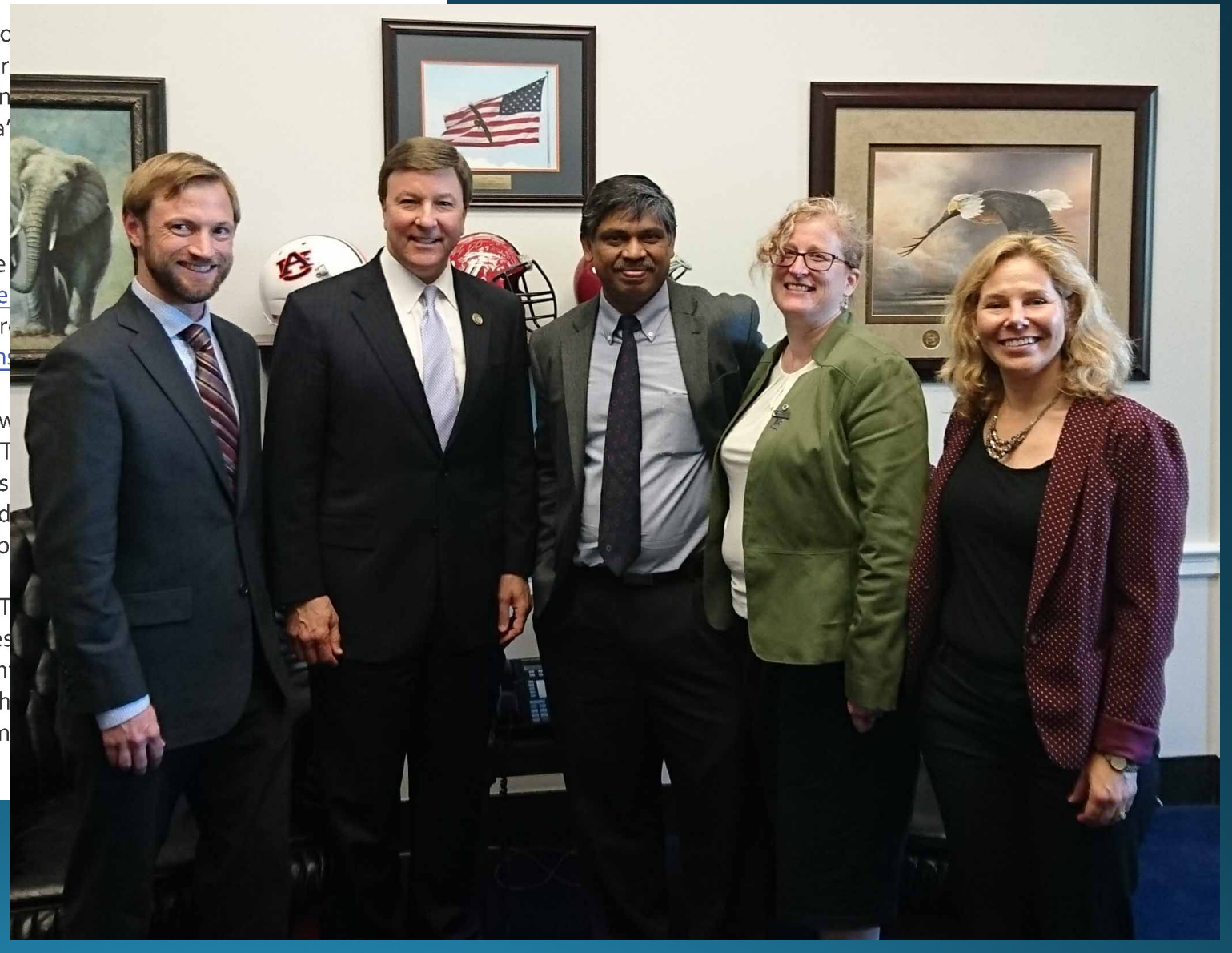




\section{Commit to the long haul}


What it's

really like to

be a voice for

science

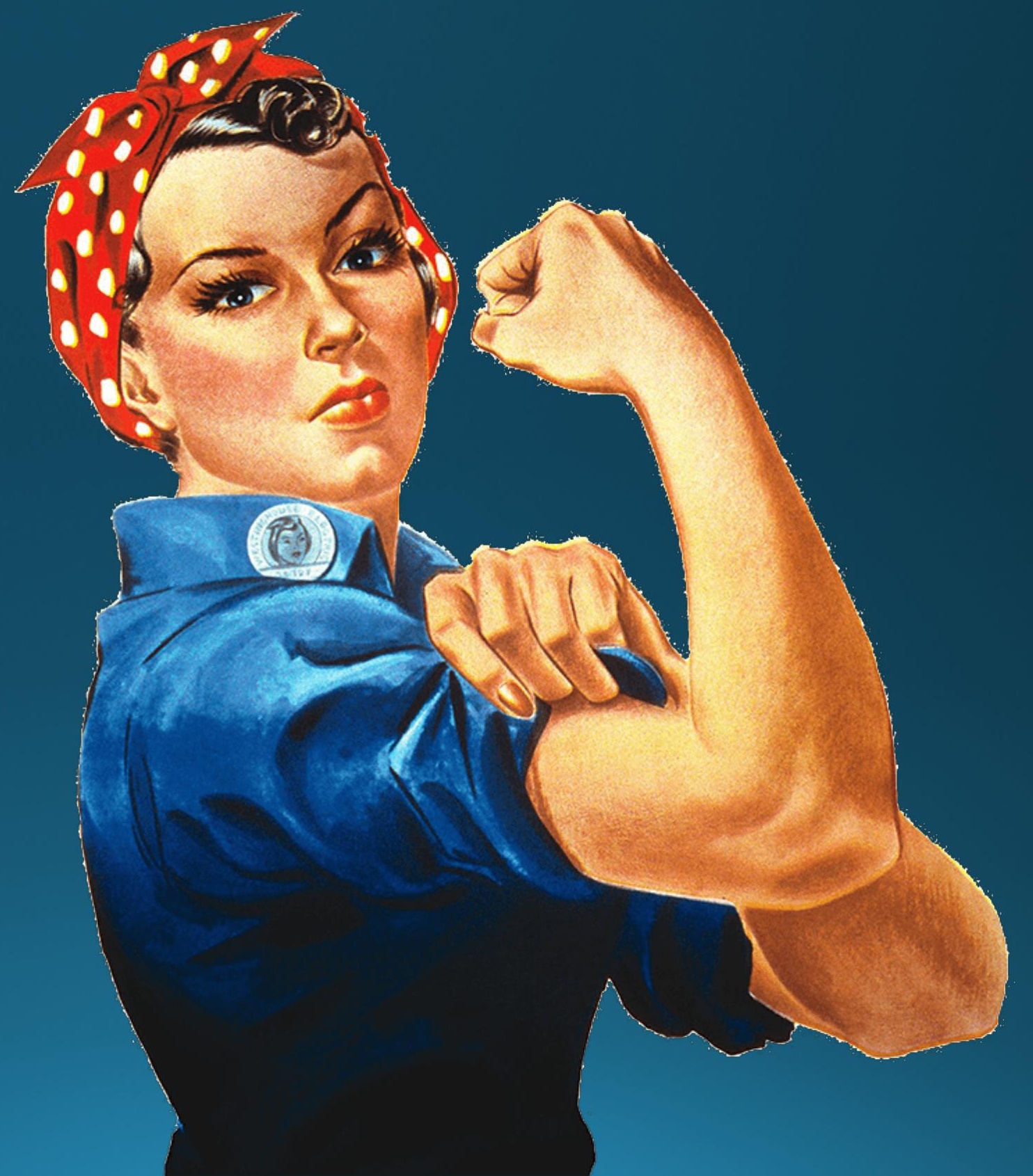




\section{Denise J. Hills \\ dhills@gsa.state.al.us}

\section{Thank you!}

Geological Society of America

Annual Meeting 2019 


\section{Denise J. Hills \\ Be a Voice for Science}

Geological Society of America

Annual Meeting 2019

T.180: "Contentious Communication from the Classroom to the Chat Room: How to Have Productive Conversations about Emotionally Charged Topics."

\section{Paper 178-1: Be a Voice for Science}

Scientists may be reluctant to speak out about contentious issues, concerned that they may not be seen as impartial or believing that "politicking" sullies their science. This reluctance has contributed to the erosion of public trust and support of science. However, it is possible to be an advocate for science while maintaining (or even increasing) trust and respect for scientific research and the scientific researcher.

The Geological Survey of Alabama (GSA) is mandated to explore for, characterize, and report Alabama's natural resources in support of economic development, conservation, management, and public policy for the betterment of Alabama's citizens, communities, and businesses. As GSA employees, we are called to provide the necessary information so that all stakeholders can make prudent decisions.

When a local community learned that the GSA was conducting an evaluation on an oil sands resource near them, they became anxious and upset that resource exploitation 
was inevitable and could have significant negative impact on their lives. Through effective communication, including public meetings and townhalls and educational outreach materials, we were able to alleviate their concerns by demonstrating that we were providing them the information necessary to make their own decisions. By presenting facts in an approachable way, we became a trusted partner in their community. We explain our role as, "We can't tell you what's best for you to do, but we can provide you the information necessary so that you can make the decision that is best for you and your community and interests."

A similar approach can be used when working with other decision-makers.

Participation in programs such as Society-sponsored congressional visits days can be a great way to understand how the value of scientific research is best communicated to a policy-maker. We have found that decision-makers want input from scientists to help drive sound policies based in fact. Therefore, being a voice for science is not seen as political, but rather as an important public service. 


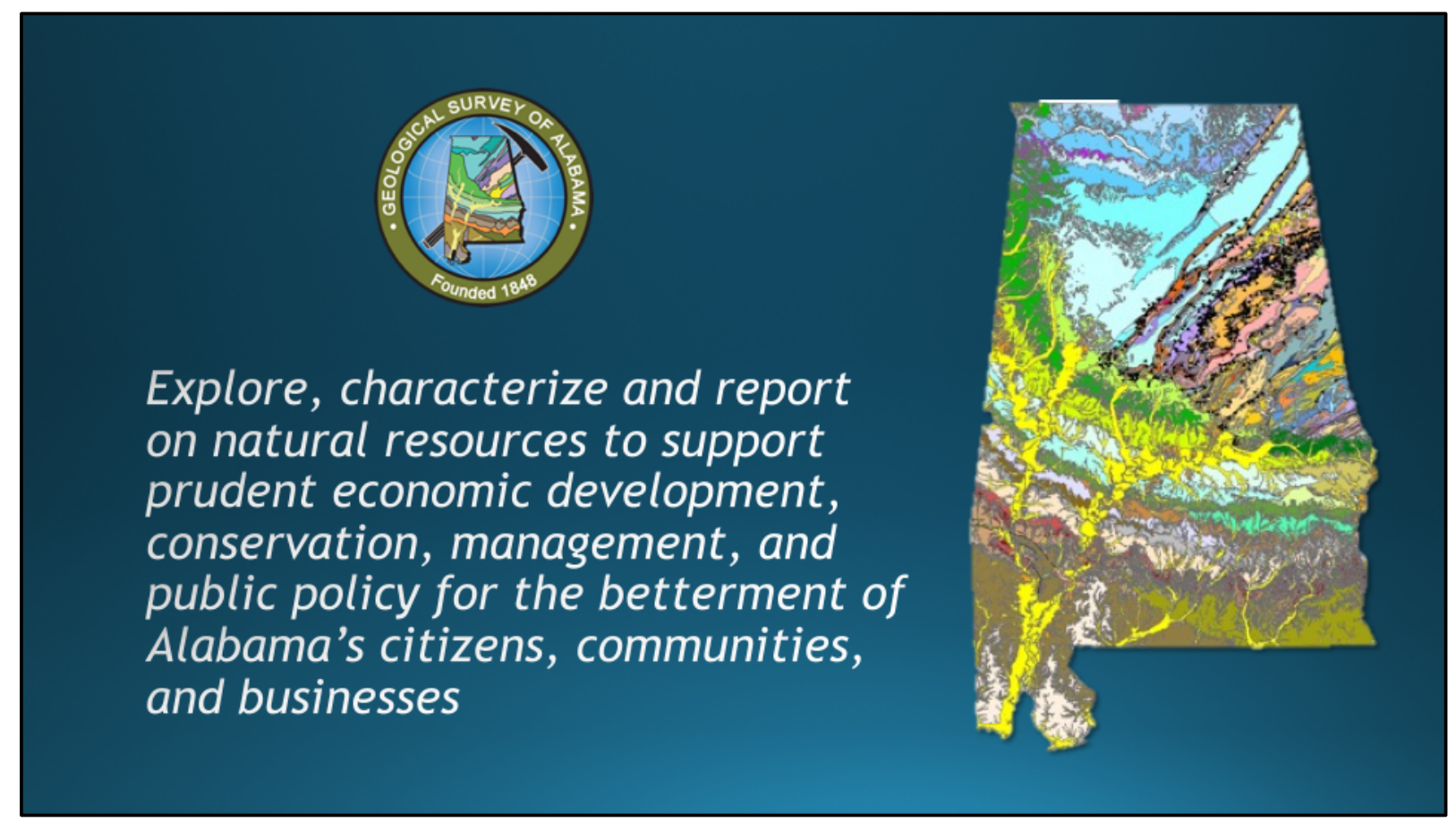

I work for the Geological Survey of Alabama, a state government agency similar in scope to the USGS, but at the state level. We have an information mandate-GSA is mandated to explore for, characterize, and report Alabama's mineral, energy, water, and biological resources in support of economic development, conservation, management, and public policy for the betterment of Alabama's citizens, communities, and businesses. 


\section{What I thought it would be like}

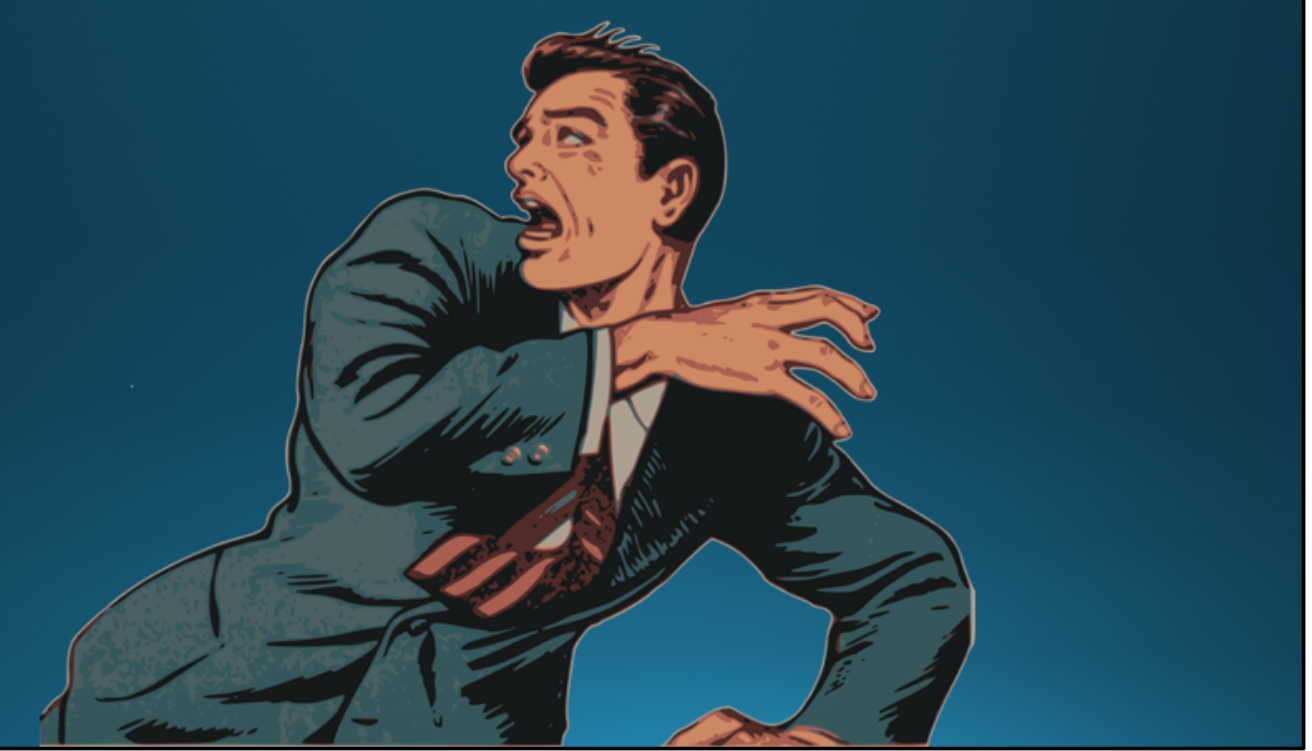

This is what I thought it might be like to advocate for science.

These are powerful, influential people! How do I talk to them? Will they even care? [OMG HUMAN INTERACTION WITH NONSCIENTISTS]

But it's part of what needs to be done.

What does this mean? It means that I have to get face to face with policy makers and other stakeholders, including everyday people, and help them understand the science behind the decisions they might need to 
make relating to natural resources.

This helps them humanize science (not many actually know "real" scientists!) It helps them connect what we do to their districts and communities. 


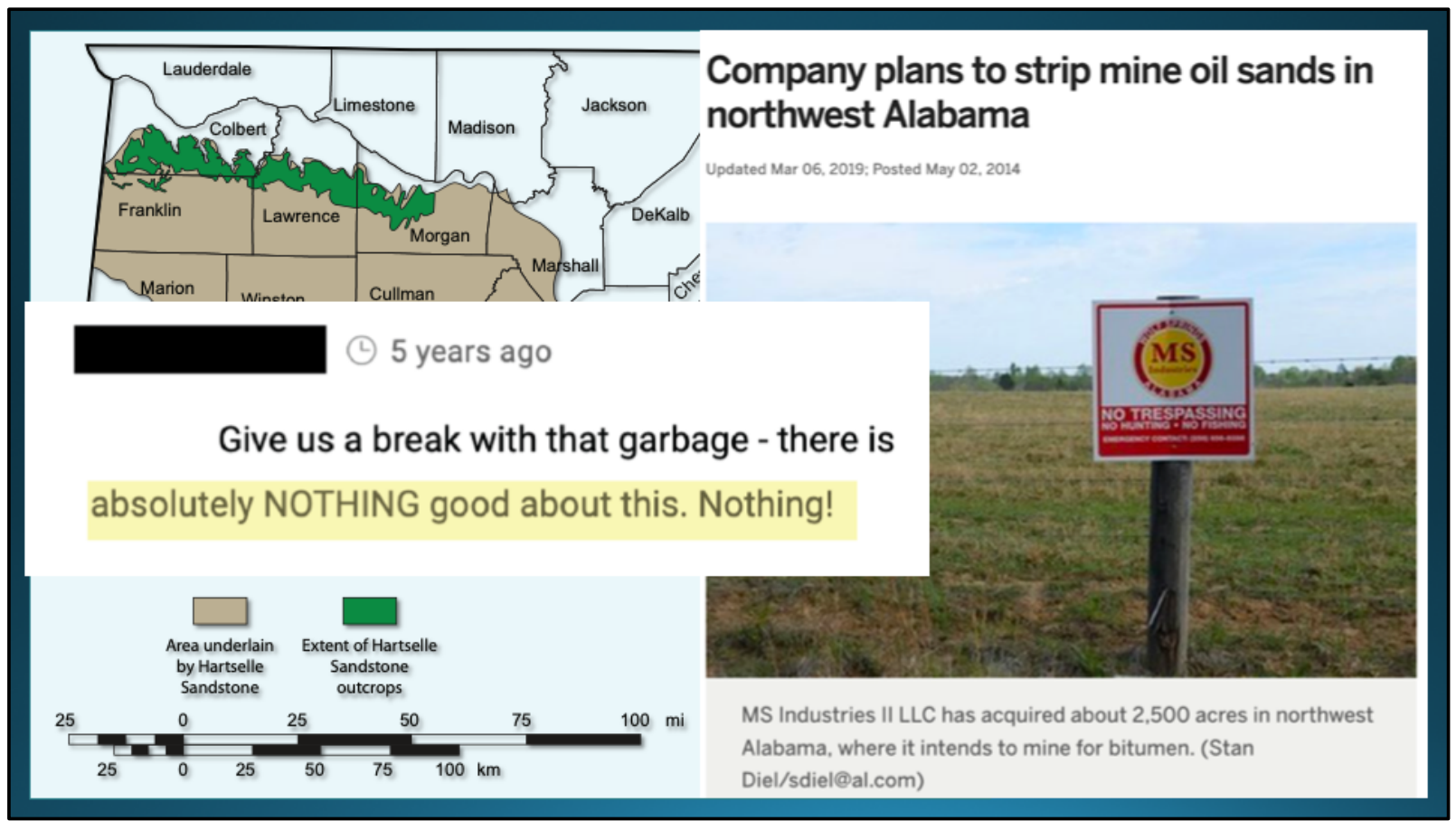

Several years ago, there was interest in researching the oil sands resource in NW Alabama. The GSA was in charge of updating the resource assessment and researching potential methods of extraction, including their efficiency and environmental impact.

This is important so that people - particularly those who live and work in the area can make informed decisions about how (or IF) development of the resource occurs. But that's not the message that was spread through the media or in the communities. [ADVANCE] For example, strip mine was never considered - [ADVANCE] and this meant the public was very distrustful of any information put out there. 


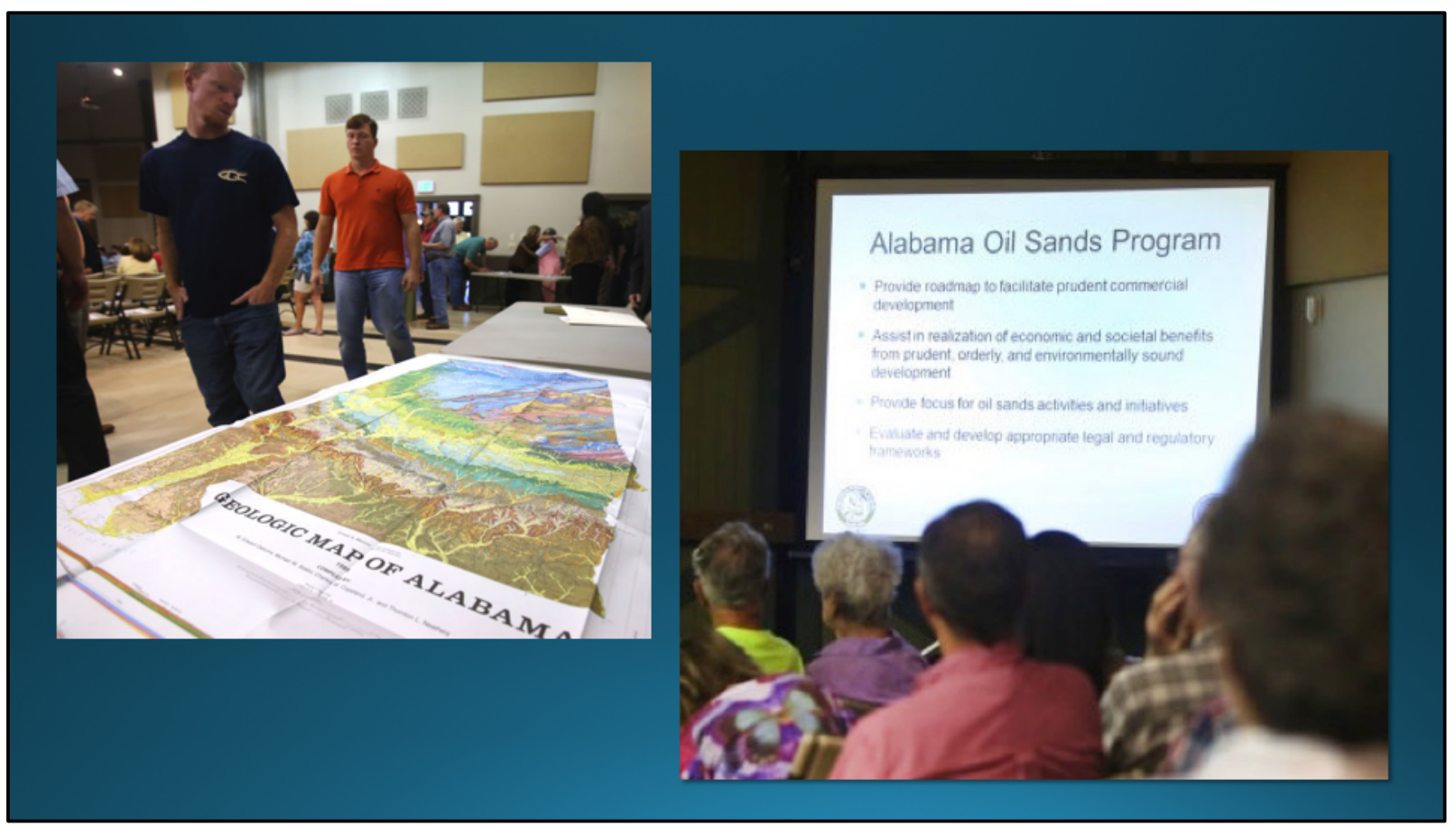

Think about what your audience needs first

The communities were concerned that their land was going to be taken away and destroyed, outside of their control. We arranged public meetings, to provide information on what we were doing and WHY.

By addressing that concern - telling them that GSA doesn't tell people or companies if they should or should not develop - we just provide the information necessary for them to decide how or even if they want to develop the resource. Without our research, citizens and investors might not have access to unbiased information necessary to make appropriate decisions.

Photos From TimesDaily.com (online version of a Florence, AL, newspaper) 


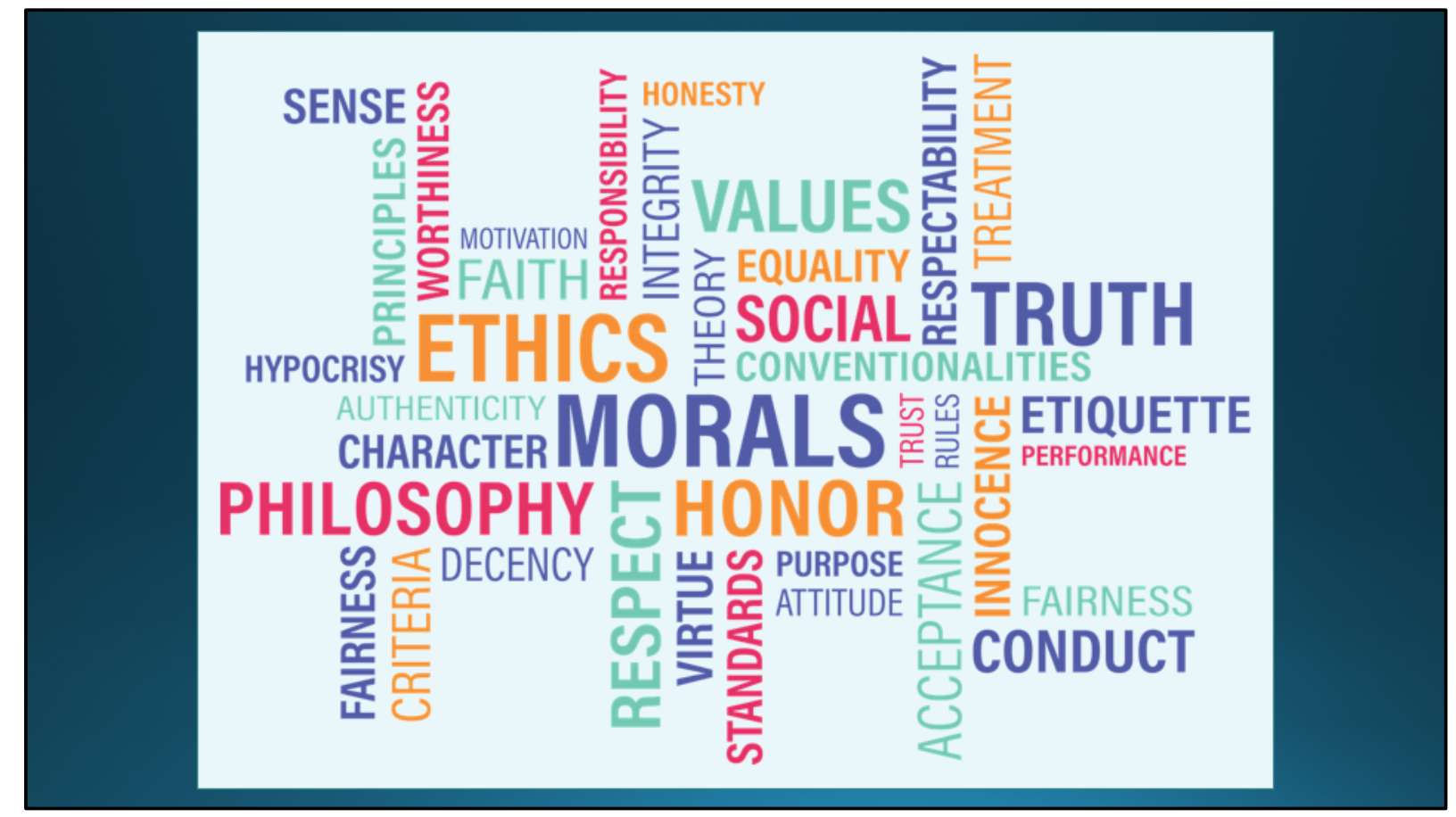

\section{What made these interactions successful?}

The key was communicating with them on their terms - by drawing on shared values; by highlighting the impact on their constituents/communities - we were able to make connections.

AGU has GREAT resources - their toolkits are useful and easy to follow. Webinars such as this are a huge benefit.

Build upon shared values - tell a story - flip the pyramid. 


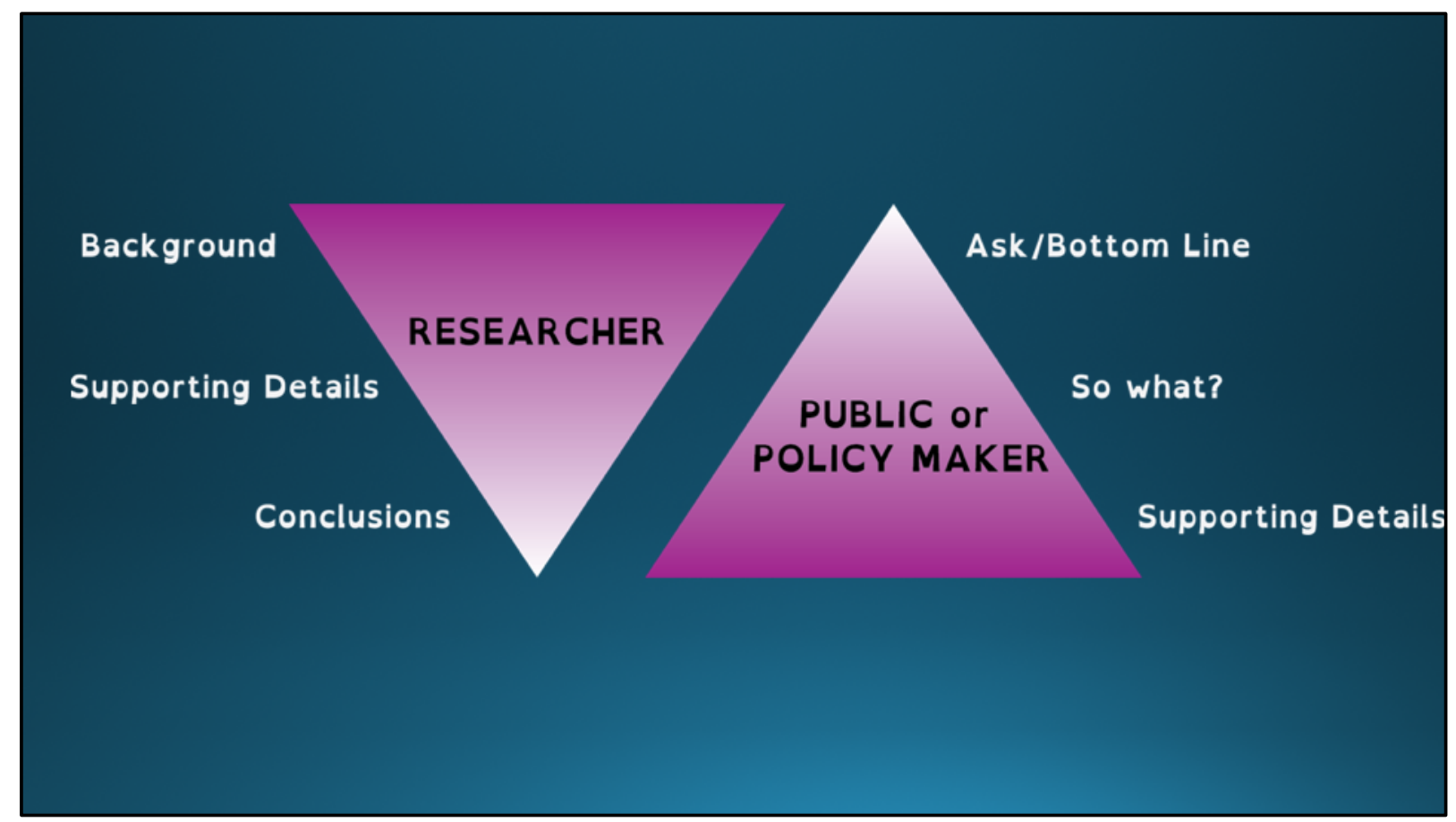

Another effective way of communicating is to "flip the pyramid" - put your main point first.

Provide more details if there's time and interest.

AGU, GSA, AAAS all have GREAT resources - their toolkits are useful and easy to follow. Webinars such as this are a huge benefit.

Build upon shared values - tell a story - flip the pyramid. 


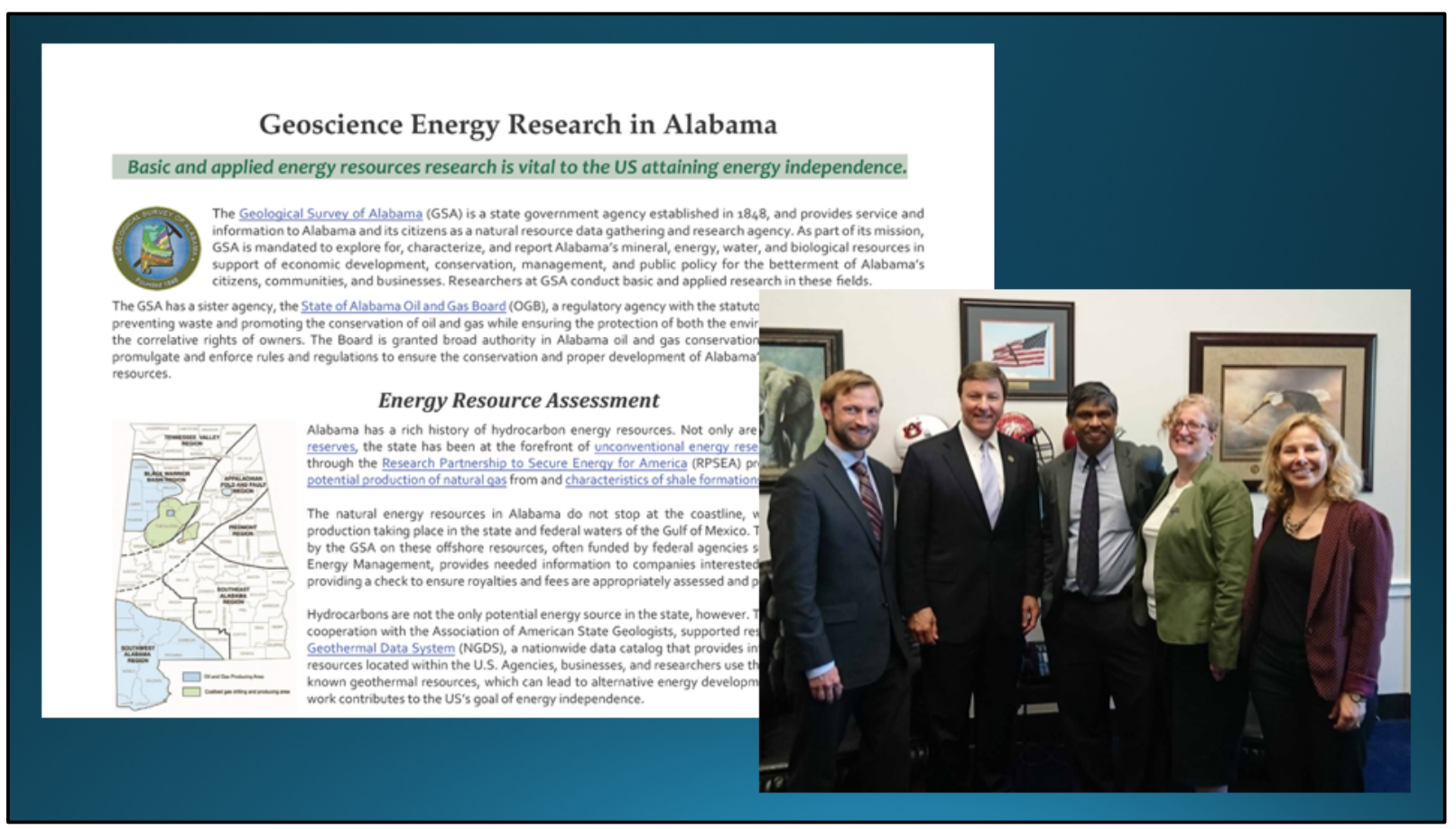

Let me share another story - working with federal legislators. You might think that talking with the public and talking with legislators is really different, but it's not.

Ask for what you want immediately. Don't get bogged down in detail. Leave information behind.

Meetings with policy makers aren't scary! They're people just like you and me. Typically, you won't even be meeting directly with the legislator, but rather their staff.

And truly, they do want to meet with us. Any time the staff can rely on someone to give them useful information, they 
appreciate it. Often staffers are responsible for many different issues, and don't have time to stay up to date on every single one.

REDIRECT back to your points if they try to get you sidetracked. (Share story of Rep. Brooks)
AL team (Adam Kobelski, Prabhakar Clement, and Denise Hills), with Rep. Mike Rogers (R-Tuskegee, $2^{\text {nd }}$ from left), and Lexi Schultz (AGU, Director of Public Affairs). 


\section{Commit to the long haul}

And finally:

Remember - this is a marathon not a sprint. If your first interaction doesn't go as well as you'd hoped, try again learning from your experience. Be sure to follow up with the office or point of contact after your face to face visit, and continue to develop that relationship! I've been following up with the offices I've visited and had very positive responses. I haven't yet scheduled any district visits, but I'm working with several offices to figure out what might fit with both our schedules. 


\section{What it's}

really like to be a voice for science

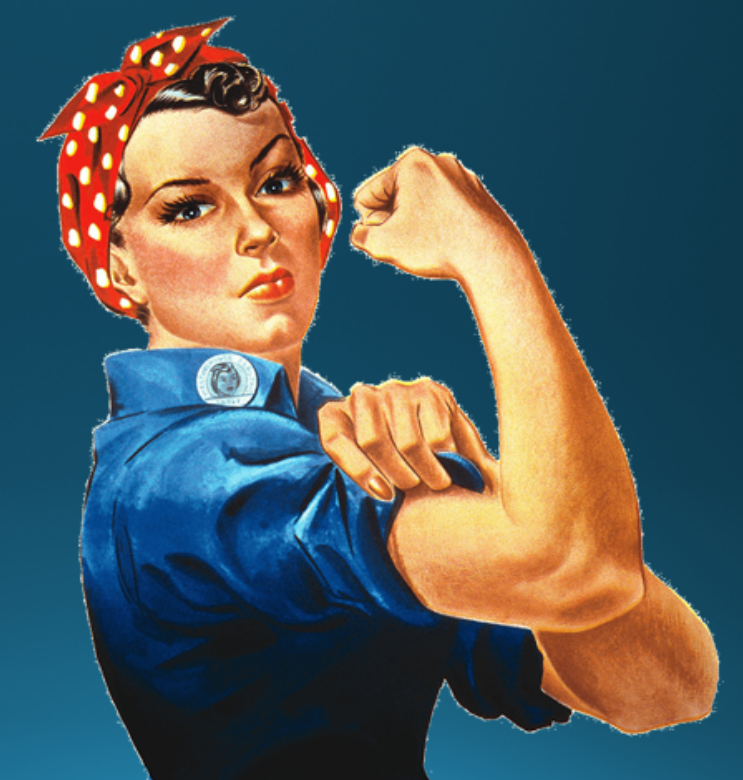

So empowering!

The staff were always courteous and friendly. Even more so they were interested, and sometimes even EXCITED, about what we had to share.

It wasn't always easy - sometimes the questions were a bit more blunt that I was expecting (for example, "Should I cut entitlements like Medicaid to fund your science?") - but no one was flat out "anti-science" 
Denise J. Hills

dhills@gsa.state.al.us

\section{Thank you!}

Geological Society of America

Annual Meeting 2019 